International Journal of Engineering \& Technology, $7(4.33)(2018) 219-222$
SPC
Website: $w w w . s c i e n c e p u b c o . c o m / i n d e x . p h p / I J E T$
Research paper

\title{
Improvement Branch Line Coupler Isolation in S Band Frequency
}

\author{
Yudi Barnadi*, Yanyan Agustian, Fuad Hasan \\ Widyatama University, Electrical Engineering Department, Indonesia \\ *Corresponding author E-mail: yudi.barnadi@widyatama.ac.id
}

\begin{abstract}
In this paper, the research was conducted to investigate the effects of optimization dimension to the isolation value of the Branch line coupler. The isolation is very important because it affects to the performance of the duplexer. The smaller value the better isolation performance of the duplexer. This research is carried out by modifying the length and width of the channels of the impedance of the Coupler. In this experiment, Branch-Line coupler is designed in the form of microstrip and fabricated using the FR-4 substrate that has a dielectric constant of 4.6, thickness of $1.3 \mathrm{~mm}$, and $3 \mathrm{GHz}$ operating frequency. To get the optimization value of the isolation characteristic, impedance channel must be modified, which are the length and width of the arms series $\left(\mathrm{Z}_{0}=50 \Omega\right)$, the length and width of the arms series $\left(Z_{0}=35.35 \Omega\right)$, and the length and width of the arms shunt $\left(Z_{0}=50 \Omega\right)$. The optimized result of the isolation is $-67,786 \mathrm{~dB}$.
\end{abstract}

Keywords: Radar; S-Band; Coupler and Isolation value.

\section{Introduction}

Branch Line Coupler is one of series of important passive microwave, usually serves as a divider or combiner power in a subsystem of communication devices or radar [1]. This device is implemented with a variety of ways to acquire capabilities. Branch Line Coupler generally consists of four ports which the ideal one would have matched, not having losses and reciprocal. Basically, Branch Line Coupler is a passive device with four terminals that have 4 pieces of arms linear symmetrical to produce output signal 90 different phase [1]. Branch Line Coupler performance is determined by parameters such as return loss, insertion loss, coupling factor and isolation. The duplexer is one of the application of the Branch Line coupler, duplexer is one part of the pulses radar. Pulse radar has only one antenna which is used to transmit and receive signals. In [2], it was described the ability of duplexer for separating the transmitted signal and the received signal

The conventional Branch Line Coupler basically have large enough dimensions and have the isolation value less than $-20 \mathrm{~dB}$, but in high frequencies this isolation value $(-20 \mathrm{~dB})$ cannot be used because of the many signals with different phase angle [3]. The purpose of this study was to obtain better isolation of the Branch Line Coupler (less than $-55 \mathrm{~dB}$ ).

In another study, similar parallel microstrip coupler has been widely used because it was easily made and has a simple shape [4]. Weakness and lack of good isolation and directivity of a microstrip because inhomogeneous dielectric constant, causing an odd mode wave propagation faster than even mode on the microstrip line [5]. Several methods have been made to improve the isolation value of this microstrip coupler. To reduce the phase velocity, wave propagation mode is used a dielectric overlay.

To improve the isolation value of the coupler can be done by adding ground plane aperture, this method can fix isolation on conventional coupler, but because of difficulties in the fabrication, this technique cannot be done in the form of MMIC [9/6]. There are several ways to generate high isolation value namely the technique of modifying the channel impedance as the feed forward technique, which is done by modifying the dimensions of the Tjunction Branch Line Coupler. Dimensional change is necessary to produce a structure size that can produce the best isolation characteristics. Research topics have been selected to obtain the appropriate size that can provide the best isolation value. The sizes of Branch Line Coupler consist of a length and width of the series arm and parallel arm, the arm has a series $Z_{0}=50 \Omega$ impedance and $Z_{o}=35.35 \Omega$ and parallel arm $Z_{o}=50 \Omega$.

On the application of radio frequency (RF) and microwave radiation, it is required to obtain a high speed. These applications offer a high level of integration to reduce the size, weight and lower power consumption [3]. Components on the form of Monolithic Microwave Integrated-Circuit (MMIC) [7] and Multilayer thinfilm multichip module technology (MCM-D) [8], which is integrated in the form of microstrip [6] and T / R switching circuit [9]. it is necessary to design integration of the active and the passive component. Besides lumped element, distributed elements, such as branch-line coupler, is an essential element necessary for it to be integrated in microwave systems. However, the integration methods of the components mentioned above is resulted in a low isolation values below $-20 \mathrm{~dB}$. In simultaneously $\mathrm{Tx} / \mathrm{Rx}$ applications where the ability to separate the signals between transmitted and received signals, it is required a high isolation because of the received signal at the receiver port is often very weak. [10].

In [10], antennas that transmit and receive signals in a different state of polarization. This is to obtain the right signal by means of the sender and receiver in a single carrier frequency. In [11], branch-line coupler was used as a separator between the sender and receiver, branch-line divides the input power coupler on one port into two ports are the same as the phase difference $+90^{\circ}$ or $90^{\circ}$. This can be used to acquire the right side (right hand side) and the left side (left-hand side) circular polarization by using two cross-polarization antenna input. In [11], it is also used two variable capacitance diodes on a circuit which is useful as tuning to 
obtain the desired operating frequency. The simulation obtained an isolation improvement of $-52 \mathrm{~dB}$ [12]. The dimension modification of branch-line coupler at the $\mathrm{T}$ junction with the physical

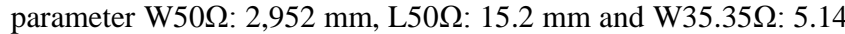
$\mathrm{mm}, \mathrm{L} 35.35 \Omega$ : $15.2 \mathrm{~mm}$ has a simulation results obtained isolation value of $-31.185 \mathrm{~dB}$. In [13], it is used a form of slot-coupled patch directional coupled that have ellipse-shaped patches with $22.5 \mathrm{~mm}$ arm length, substrate dielectric constant 4003C Rogers Ro 3.38 at the working frequency of $2 \mathrm{GHz}$, has $-45 \mathrm{~dB}$ isolation. In this study, Branch-Line coupler is applied in the form of microstrip with the substrate used is FR-4 that has a dielectric constant of 4.6 and a thickness of $1.3 \mathrm{~mm}$ with operating frequency of $3 \mathrm{GHz}$. We used FR-4 because it is easily obtained in the market. To obtain the best isolation value, we optimize of the transmission line coupler by modifying the length and width of the arms series $(Z o=50 \Omega)$, the length and width of the arms series $(\mathrm{Zo}=35.35$ $\Omega)$, the length and width of the arms parallel $(\mathrm{Zo}=50 \Omega)$ using CST software of 2014. The simulation optimization result of isolation value is $-67.786 \mathrm{~dB}$.

\section{Proposed Branch line coupler}

Geometry of the proposed Branch line coupler is showed in Fig. 1. It is fed by $50 \Omega$ connector and designed on a FR- 4 dielectric substrate of 4.6 with $1.3 \mathrm{~mm}$ thickness

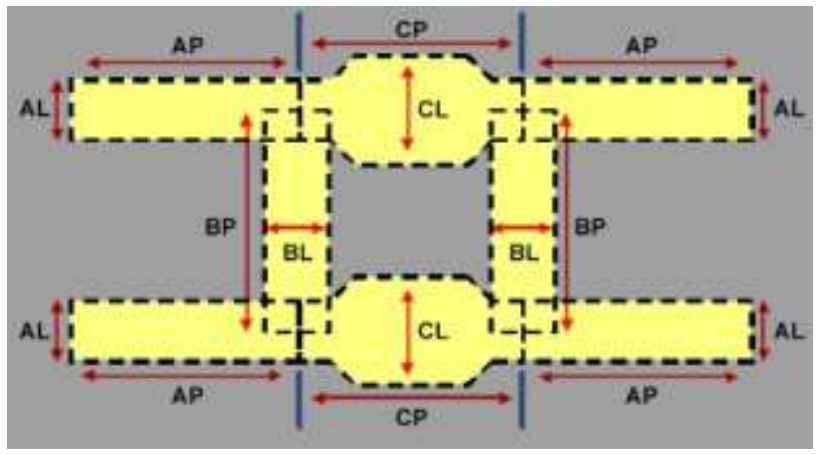

Fig. 1: Geometry of Branch line coupler [5]

where:

$\mathrm{AP}=$ The length of the transmission line (TL) A (mm)

$\mathrm{BP}=$ The length of the transmission line (TL) $\mathrm{B}(\mathrm{mm})$

$\mathrm{CP}=$ The length of the transmission line (TL) $\mathrm{C}(\mathrm{mm})$

$\mathrm{AL}=$ The width of the transmission line (TL) A (mm)

$\mathrm{BL}=$ The width of the transmission line $(\mathrm{TL}) \mathrm{B}(\mathrm{mm})$

$\mathrm{CL}=$ The width of the transmission line (TL) $\mathrm{C}(\mathrm{mm})$

This research begins with a calculation of the dimensions of the conventional BLC formula. This initial design calculation will be examined in the simulation. Modification on BLC dimensions is conducted as a way to obtain optimum results in simulation, then the optimum design will be fabricated. The BLC is designed using $90^{\circ}$ Hybrid Coupler, with a resonant frequency at $3 \mathrm{GHz}$.

\section{Methodology}

\subsection{Calculation of the Length of the transmission line}

The length (L) of the coupler usually equal to a quarter of wavelength which propagate in material as follow [10-11]:

$$
\begin{aligned}
& \lambda \mathrm{g}=\frac{\mathrm{c}}{\mathrm{fX} \sqrt{\mathrm{gI}}} \\
& \lambda \mathrm{d}=\frac{\lambda \mathrm{g}}{4}
\end{aligned}
$$

where $\mathrm{f}$ is operating frequency of the coupler, and $\mathrm{gr}$ is dielectric constant of the substrate.

\subsection{Calculation of the Width transmission line}

$$
\frac{W}{d}=\frac{B^{d}}{e^{2 \pi}-2}
$$

where $\mathrm{Z}_{\mathrm{o}}$ is $50 \Omega$ and $35,35 \Omega$

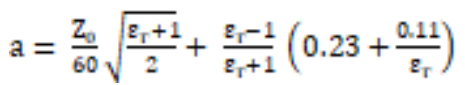

From calculation of the above formulas, there were obtained the dimension of $\mathrm{AP}=\mathrm{BP}=\mathrm{CP}=11.66 \mathrm{~mm}, \mathrm{AL}=\mathrm{BL}=2.398 \mathrm{~mm}$, $\mathrm{CL}=4.125 \mathrm{~mm}$

\subsection{Optimization Procedure:}

The optimization of the coupler to determine the effect changes in the length and width of the transmission line A, B and C branchline coupler to the isolation value.

\subsection{Procedure}

1. The length of the transmission line A (AP-1) is reduced from $11.66 \mathrm{~mm}, 11.55 \mathrm{~mm}, 11.50 \mathrm{~mm}, 11.48 \mathrm{~mm}, 10.50 \mathrm{~mm}$ and last $10.48 \mathrm{~mm}$, but the length of the transmission line $\mathrm{BP}, \mathrm{CP}$, and the width of the transmission line Al, BL and CL does not change (the same as the value of the results of the calculation), this can be seen in Table 1 .

Table 1 the iength reduction effect of the transmision Ine A (AP-1)
\begin{tabular}{|c|c|c|c|c|c|c|c|c|}
\hline NO & $\begin{array}{c}\text { AP-1 } \\
(\mathrm{mm})\end{array}$ & $\begin{array}{c}\text { BP } \\
(\mathrm{mm})\end{array}$ & $\begin{array}{c}\mathrm{CP} \\
(\mathrm{mm})\end{array}$ & $\begin{array}{c}\text { AL. } \\
(\mathrm{mm})\end{array}$ & $\begin{array}{c}\text { BL } \\
(\mathrm{mm})\end{array}$ & $\begin{array}{c}\text { C. } \\
(\mathrm{mm})\end{array}$ & $\begin{array}{c}\text { Freq } \\
(\mathrm{GHz})\end{array}$ & $\begin{array}{c}5.41 \\
(\mathrm{~dB})\end{array}$ \\
\hline 1 & 11.66 & 11.66 & 11.66 & 2.398 & 2.398 & 4.125 & 2.814 & -34.366 \\
\hline 2 & 11.55 & 11.66 & 11.66 & 2.398 & 2.398 & 4.125 & 2.816 & -34.159 \\
\hline 3 & 11.50 & 11.66 & 11.66 & 2.398 & 2.398 & 4.125 & 2.817 & -34.009 \\
\hline 4 & 11.48 & 11.66 & 11.66 & 2.398 & 2.398 & 4.125 & 2.818 & -33.947 \\
\hline 5 & 10.50 & 11.66 & 11.66 & 2.398 & 2.398 & 4.125 & 2.819 & -30.031 \\
\hline
\end{tabular}

2. The length of the transmission line A (AP-2) was reduced from $10.45 \mathrm{~mm}, 10.40 \mathrm{~mm}, 10.38 \mathrm{~mm}, 10.37 \mathrm{~mm}, 10.36 \mathrm{~mm}, 10.35$ $\mathrm{mm}$, but the length of the transmission line $\mathrm{BP}, \mathrm{CP}$, and the width of the line length $\mathrm{Al}, \mathrm{BL}$ and $\mathrm{CL}$ does not change (the same as the value of the results of the calculation), this can be seen in Table 2 .

Tabel 2 The lenets reduction eflec of the transmision liae A (MP-2)
\begin{tabular}{|c|c|c|c|c|c|c|c|c|}
\hline NO & $\begin{array}{c}\text { AP-2 } \\
(\mathrm{mm})\end{array}$ & $\begin{array}{c}\text { BP } \\
(\mathrm{mm})\end{array}$ & $\begin{array}{c}\mathrm{CP} \\
(\mathrm{mm})\end{array}$ & $\begin{array}{c}\text { AL } \\
(\mathrm{mm})\end{array}$ & $\begin{array}{c}\mathrm{BL} \\
(\mathrm{mm})\end{array}$ & $\begin{array}{c}\text { C. } \\
(\mathrm{mm})\end{array}$ & $\begin{array}{c}\text { Freq } \\
(\mathrm{GHz})\end{array}$ & $\begin{array}{c}5.41 \\
(\mathrm{~dB})\end{array}$ \\
\hline 1 & 10.45 & 11.66 & 11.66 & 2.398 & 2.398 & 4.125 & 2.820 & -30.036 \\
\hline 2 & 10.40 & 11.66 & 11.66 & 2398 & 2.398 & 4.125 & 2.823 & -30.014 \\
\hline 3 & 10.38 & 11.66 & 11.66 & 2.398 & 2.398 & 4.125 & 2.824 & -30.007 \\
\hline 4 & 10.37 & 11.66 & 11.66 & 2.398 & 2.398 & 4.125 & 2.824 & -30.001 \\
\hline 5 & 10.36 & 11.66 & 11.66 & 2.398 & 2.398 & 4.125 & 2.824 & -29.996 \\
\hline 6 & 10.35 & 11.66 & 11.66 & 2.398 & 2.398 & 4.125 & 2.824 & -29.990 \\
\hline
\end{tabular}

3.The length of the transmission line A (AP-1) and B (BP-1) is reduced, but the length of the transmission line $\mathrm{C}(\mathrm{CP})$, and the width of the transmission line $\mathrm{Al}, \mathrm{BL}$ and $\mathrm{CL}$ does not change (the same as the value of the calculation result), this can be seen in Table 3.

Tabel 3 The length reduction effect of the transmiaion Ine $\mathrm{A}[\mathrm{BP}-1]$
\begin{tabular}{|c|c|c|c|c|c|c|c|c|}
\hline NO & $\begin{array}{c}\text { AP-1 } \\
(\mathrm{mm})\end{array}$ & $\begin{array}{c}\mathrm{BP}-1 \\
(\mathrm{~mm})\end{array}$ & $\begin{array}{c}\mathrm{CP} \\
(\mathrm{mm})\end{array}$ & $\begin{array}{c}\text { AL } \\
(\mathrm{mm})\end{array}$ & $\begin{array}{c}\mathrm{BL} \\
(\mathrm{mm})\end{array}$ & $\begin{array}{c}\mathrm{CL} \\
(\mathrm{mm})\end{array}$ & $\begin{array}{c}\text { Freq } \\
(\mathrm{GH})\end{array}$ & $\begin{array}{c}5.41 \\
(\mathrm{~dB})\end{array}$ \\
\hline 1 & 11.55 & 11.56 & 11.66 & 2.398 & 2.398 & 4.125 & 2.820 & -34.286 \\
\hline 2 & 11.50 & 11.50 & 11.66 & 2.398 & 2.398 & 4.125 & 2.825 & -34.266 \\
\hline 3 & 11.48 & 11.48 & 11.66 & 2.398 & 2.398 & 4.125 & 2.830 & -34.314 \\
\hline 4 & 10.50 & 10.50 & 11.66 & 2.398 & 2.398 & 4.125 & 2.852 & -33.966 \\
\hline 5 & 10.48 & 10.48 & 11.66 & 2.398 & 2.398 & 4.125 & 2.920 & -30.965 \\
\hline
\end{tabular}

4. The length of the transmission line A (AP-2) and B (BP-2) is reduced, but the length of the transmission line $\mathrm{CP}$, and the width 
of the transmission line $\mathrm{Al}, \mathrm{BL}$ and $\mathrm{CL}$ does not change (the same as the value of the results of the calculation), this can be seen in Table 4 .

Tabel 4 The ienist reduction eflect of the transmivion the B|BP-2|

\begin{tabular}{|c|c|c|c|c|c|c|c|c|}
\hline NO & $\begin{array}{c}\text { AP-2 } \\
(\mathrm{mm})\end{array}$ & $\begin{array}{c}\mathrm{BP}-2 \\
(\mathrm{~mm})\end{array}$ & $\begin{array}{c}\mathrm{CP} \\
(\mathrm{mm})\end{array}$ & $\begin{array}{c}\text { AL } \\
(\mathrm{mm})\end{array}$ & $\begin{array}{c}\text { BL } \\
(\mathrm{mm})\end{array}$ & $\begin{array}{c}\mathrm{CL} \\
(\mathrm{mm})\end{array}$ & $\begin{array}{c}\text { Freq } \\
(\mathrm{GHz})\end{array}$ & S.41(dB) \\
\hline 1 & 10.45 & 10.47 & 11.66 & 2.398 & 2.398 & 4.125 & 2.927 & -31.017 \\
\hline 2 & 10.40 & 10.46 & 11.66 & 2.398 & 2.398 & 4.125 & 2.930 & -31.007 \\
\hline 3 & 10.38 & 10.40 & 11.66 & 2.398 & 2.398 & 4.125 & 2.940 & -31.075 \\
\hline 4 & 10.37 & 10.38 & 11.66 & 2.398 & 2.398 & 4.125 & 2.942 & -31.060 \\
\hline 5 & 10.36 & 10.37 & 11.66 & 2.398 & 2.398 & 4.125 & 2.946 & -30.996 \\
\hline 6 & 10.35 & 10.36 & 11.66 & 2.398 & 2.398 & 4.125 & 2.950 & -30.881 \\
\hline
\end{tabular}

5. The length of transmision line A (AP-2) and B (BP-2) reduced, how ever transmision line C(CL-1) increased from 4.037, 4.200, 4.600, 4.600, 4.800, 4.900. From table below frequency increased from $2.835 \mathrm{GHz}, 2.865,2.843 \mathrm{GHz}, 2.853 \mathrm{GHz}$, and $2.948 \mathrm{GHz}$, this can be seen in Table 5 .

Tated 5 The width addeion eflect of the transmision line $(10-1)$

\begin{tabular}{|c|c|c|c|c|c|c|c|c|}
\hline NO & $\begin{array}{c}\text { AP-1 } \\
(\mathrm{mm})\end{array}$ & $\begin{array}{c}\mathrm{BP}-1 \\
(\mathrm{~mm})\end{array}$ & $\begin{array}{c}\mathrm{CP}-1 \\
(\mathrm{~mm})\end{array}$ & $\begin{array}{c}\text { AL-1 } \\
(\mathrm{mm})\end{array}$ & $\begin{array}{c}\mathrm{BL}-1 \\
(\mathrm{~mm})\end{array}$ & $\begin{array}{c}\text { CL-1 } \\
(\mathrm{mm})\end{array}$ & $\begin{array}{c}\text { Freq } \\
{[\mathrm{GHz})}\end{array}$ & $\mathbf{5 . 4 1 ( \mathrm { dB } )}$ \\
\hline 1 & 11.55 & 11.56 & 11.53 & 2.38 & 2.36 & 4.037 & 2.835 & -31.837 \\
\hline 2 & 11.50 & 11.50 & 11.43 & 2.48 & 2.40 & 4.200 & 2.865 & -27.474 \\
\hline 3 & 11.48 & 11.48 & 11.40 & 2.52 & 2.46 & 4.600 & 2.843 & -28.583 \\
\hline 4 & 10.50 & 10.50 & 11.35 & 2.56 & 2.56 & 4.800 & 2.853 & -35.082 \\
\hline 5 & 10.48 & 10.48 & 10.50 & 2.58 & 2.66 & 4.900 & 2.948 & -30.256 \\
\hline
\end{tabular}

6. The length of the transmission line A (AP-2), B (BP-2), C (CP2 ) are reduced, but the width of the transmission line $\mathrm{A}(\mathrm{AL}-2), \mathrm{B}$ (BL-2) and C ( CL-2) increases from $5.000 \mathrm{~mm}, 5.020 \mathrm{~mm}, 5.040$ $\mathrm{mm}, 5.050 \mathrm{~mm}, 5.060$ and last $5.067 \mathrm{~mm}$. However, the width of the transmission line C (CL) does not change (the same as the value of the results of the calculation), this can be seen in Table 6 .

Tabel 6 The width oddition effect of the transmision Ine CicL-2)

\begin{tabular}{|c|c|c|c|c|c|c|c|c|}
\hline NO & $\begin{array}{l}\text { AP-2 } \\
(\mathrm{mm})\end{array}$ & $\begin{array}{l}B P-2 \\
(\mathrm{~mm})\end{array}$ & $\begin{array}{l}C P-2 \\
(\mathrm{~mm})\end{array}$ & $\begin{array}{l}\text { Al-2 } \\
(\mathrm{mm})\end{array}$ & $\begin{array}{l}8 \mathrm{BL}-2 \\
(\mathrm{~mm})\end{array}$ & $\begin{array}{c}\mathrm{Cl}-2 \\
(\mathrm{~mm})\end{array}$ & $\begin{array}{l}\text { Freq } \\
(\mathrm{GHz})\end{array}$ & $S .41(\mathrm{~dB})$ \\
\hline 1 & 10.45 & 10,47 & 10.30 & 2.68 & 2.76 & 5.000 & 2.980 & -38.830 \\
\hline 2 & 10.40 & 10.46 & 10.20 & 70 & 2.8 & 3 & 2.980 & 28 \\
\hline 3 & 10.38 & 10.40 & 10.26 & 2.75 & 2.83 & 5.040 & 2.998 & -45.658 \\
\hline 4 & 10.37 & 10.38 & 10.25 & 2.76 & 2.84 & 5.050 & 3.000 & 48,058 \\
\hline 5 & 10.36 & 10.37 & 10.24 & 2.77 & 2.85 & 5.060 & 3.000 & -51.042 \\
\hline 6 & 10.35 & 10.36 & 10.23 & 2.78 & 2.86 & 5.067 & 3.000 & -67.786 \\
\hline
\end{tabular}

The optimal dimension with the best isolation value obtained are when $\mathrm{AP}-2=10.35 \mathrm{~mm}, \mathrm{BP}-2=10.36 \mathrm{~mm}, \mathrm{CP}-2=10.23 \mathrm{~mm}$, $\mathrm{AL}-2=2.78 \mathrm{~mm}, \mathrm{BL}-2=2.86 \mathrm{~mm}$ and $\mathrm{CL}-2=5.067$.

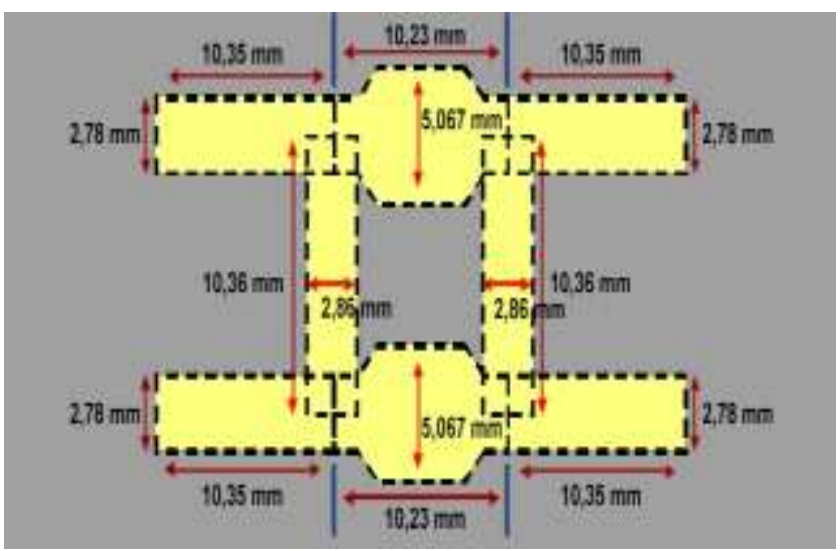

Fig. 2: Optimal dimension of Branch line coupler

The fabricated BLC can be seen at Figure 3.

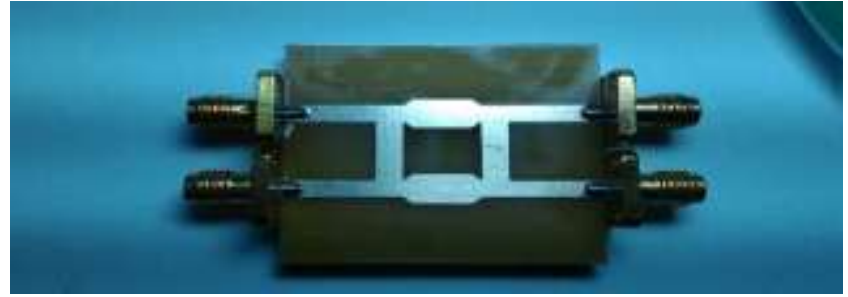

Fig. 3: Photograph of proposed Branch Line coupler

\section{Results and Discussion}

\subsection{Simulation Results}

Simulations carried out after the calculation and optimization. The result is shown in Figure 4.

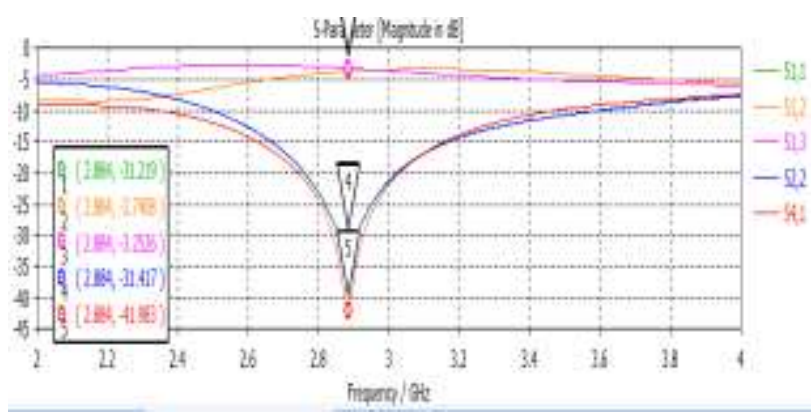

Fig. 4: Simulation result from calculation

It can be seen at Figure 4, that the operation frequency is shifted to $2.884 \mathrm{GHz}$ instead of $3 \mathrm{GHz}$. After optimization is conducted, the result is shown in Figure 5.

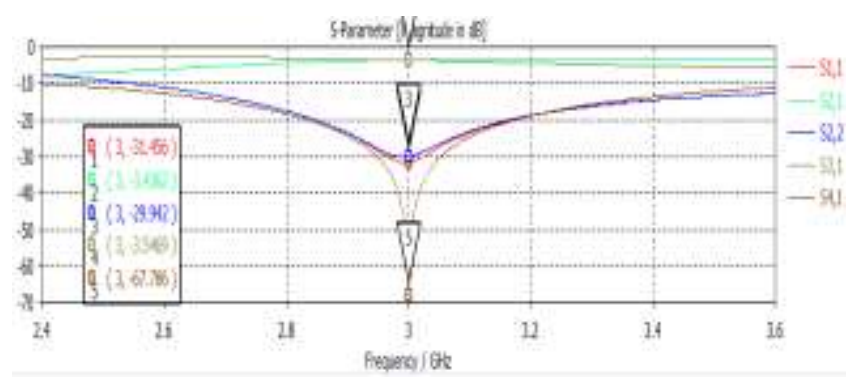

Fig. 5: Simulation result s parameter from optimal dimension

From Figure 5, The isolation obtained reach $-67.786 \mathrm{~dB}$. This is the best value of isolation.

\subsection{Comparison Dimension Calculation and Optimiza- tion Result}

The comparison of the dimension of the best isolation BLC with the conventional one can be seen at Table 7 .

Table 7: Comparison dimensions calculation result and optimization

\begin{tabular}{|c|c|c|}
\hline Variabel & $\begin{array}{c}\text { Dimension } \\
\text { calculation }\end{array}$ & $\begin{array}{c}\text { Optimization } \\
\text { dimension }\end{array}$ \\
\hline AP & $11.66 \mathrm{~mm}$ & $10.35 \mathrm{~mm}$ \\
$\mathrm{AL}$ & $2.398 \mathrm{~mm}$ & $2.78 \mathrm{~mm}$ \\
$\mathrm{BP}$ & $11.66 \mathrm{~mm}$ & $10.36 \mathrm{~mm}$ \\
\hline $\mathrm{BL}$ & $2.398 \mathrm{~mm}$ & $2.86 \mathrm{~mm}$ \\
$\mathrm{CP}$ & $11.66 \mathrm{~mm}$ & $10.23 \mathrm{~mm}$ \\
\hline $\mathrm{CL}$ & $4.125 \mathrm{~mm}$ & $5.067 \mathrm{~mm}$ \\
\hline
\end{tabular}

\section{Conclusion}

The changing dimensions of the Branch line coupler will affect the isolation value and shift the operating frequency. The change that greatly affect the isolation value is the change in the width of the 
transmission line having a serial arm of impedance $\mathrm{Zo}=35.35 \Omega$. To obtain the dimensions that the isolation value less than $-55 \mathrm{~dB}$, it can be done using optimization methods, especially the most influential is the optimization of the space. The best isolation of the improved BLC is $-67.786 \mathrm{~dB}$.

\section{References}

[1] Wirth, W. D. (2001). Radar techniques using array antennas. IET

[2] Skolnik, M. I. (1990). Radar handbook. McGraw-Hill.

[3] Ahn, B. J., Kim, S. K., \& Yook, J. O. (2005). Isolation-improved branch-line coupler based on feed-forward technique. Proceedings of the IEEE Asia-Pacific Conference on Microwave, pp. 4-pp.

[4] Moradianpour, M., \& Khalaj-Amirhosseini, M. (2008). Improvement the characteristics of the microstrip parallel coupled line coupler by means of grooved substrate. Progress in Electromagnetics Research, 3, 205-215.

[5] Moradian, M. (2015). Improving isolation of slot-coupled directional couplers. Electronics Letters, 51(12), 914-915.

[6] Willems, D. A. (1994). A broadband MMIC quadrature coupler using a braided microstrip structure. Proceedings of the IEEE MTT-S International Microwave Symposium Digest, pp. 899-902.

[7] Banba, S., \& Ogawa, H. (1995). Multilayer MMIC directional couplers using thin dielectric layers. IEEE transactions on microwave theory and techniques, 43(6), 1270-1275.

[8] Carchon, G., De Raedt, W., \& Nauwelaers, B. (2001). Integration of CPW quadrature couplers in multilayer thin-film MCM-D. IEEE Transactions on Microwave Theory and Techniques, 49(10), 17701776.

[9] Willems, D. A. (1994). A broadband MMIC quadrature coupler using a braided microstrip structure. Proceedings of the IEEE MTT-S International Microwave Symposium Digest, pp. 899-902.

[10] Hong, J. S. G., \& Lancaster, M. J. (2004). Microstrip filters for RF/microwave applications. John Wiley and Sons.

[11] Mayer, L. W., \& Scholtz, A. L. (2009). Circularly polarized patch antenna with high Tx/Rx-separation. Proceedings of the IEEE International Conference on pp. 213-216.

[12] Riyanti, I. (2010). Perancangan Microstrip Branch Line Coupler dengan T-Junction untuk Mobile WiMAX pada Frekuensi 2, $3 \mathrm{GHz}$ Skripsi S1, Universitas Indonesia.

[13] Moradian, M. (2015). Improving isolation of slot-coupled directional couplers. Electronics Letters, 51(12), 914-915. 